\title{
Effect of marriage on duration of chest pain associated with acute myocardial infarction before seeking care
}

\author{
Clare L. Atzema MD MSc, Peter C. Austin PhD, Thao Huynh MD MSc, Ansar Hassan MD PhD, Maria Chiu MSc, \\ Julie T. Wang MSc, Jack V. Tu MD PhD
}

Competing interests: Ansar Hassan has received a Grant in Aid from the Heart and Stroke

Foundation of New

Brunswick for work unrelated to this study. No competing interests were declared by the other authors.

This article has been peer reviewed.

Correspondence to: Dr. Clare Atzema, clare.atzema@ices.on.ca

CMAJ 2011. DOI:10.1503 /cmaj.110170

\begin{abstract}
Background: Coronary artery disease is the most common cause of death in the Western world, and being married decreases the risk of death from cardiovascular causes. We aimed to determine whether marital status was a predictor of the duration of chest pain endured by patients with acute myocardial infarction before they sought care and whether the patient's sex modified the effect.
\end{abstract}

Methods: We conducted a retrospective, population-based cohort analysis of patients with acute myocardial infarction admitted to 96 acute care hospitals in Ontario, Canada, from April 2004 to March 2005. We excluded patients who did not experience chest pain. Using multivariable regression analyses, we assessed marital status in relation to delayed presentation to hospital (more than six hours from onset of pain), both overall and stratified by sex. In patients who reported the exact duration of chest pain, we assessed the effect of marital status on the delay in seeking care.

Results: Among 4403 eligible patients with acute myocardial infarction, the mean age was
67.3 (standard deviation 13.6) years, and 1486 $(33.7 \%)$ were women. Almost half (2037 or $46.3 \%)$ presented to a hospital within two hours, and $3240(73.6 \%)$ presented within six hours. Overall, $75.3 \%$ (2317/3079) of married patients, $67.9 \%(188 / 277)$ of single patients, $68.5 \%(189 / 276)$ of divorced patients and $70.8 \%$ (546/771) of widowed patients presented within six hours of the onset of chest pain. Being married was associated with lower odds of delayed presentation (odds ratio [OR] 0.46, 95\% confidence interval $[\mathrm{Cl}] 0.30-0.71, p<0.001$ ) relative to being single. Among men, the OR was 0.35 (95\% Cl 0.21-0.59, $p<0.001$ ), whereas among women the effect of marital status was not significant (OR 1.36, 95\% Cl 0.49-3.73, $p=0.55$ ).

Interpretation: Among men experiencing acute myocardial infarction with chest pain, being married was associated with significantly earlier presentation for care, a benefit that was not observed for married women. Earlier presentation for medical care appears to be one reason for the observed lower risk of cardiovascular death among married men, relative to their single counterparts.

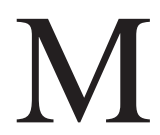

arriage has long been known to offer health benefits ${ }^{1,2}$ and is associated with a lower risk of death ${ }^{3,4}$ relative to people who are not married. The effect is more pronounced among men than among women. ${ }^{5,6}$ However, the specific mechanisms responsible for the lower rate of cardiovascular deaths in married persons ${ }^{7}$ are not known.

Effective, time-sensitive therapy for acute myocardial infarction is available, ${ }^{89}$ and delays in the emergency department and for in-hospital components of care have been substantially reduced over the past few decades. ${ }^{10.11}$ In contrast, patients' delay in seeking care for acute myocardial infarction has shown little improvement over time, ${ }^{12,13}$ despite intensive campaigns to raise public awareness. ${ }^{14,15}$ Patients' delay remains by far the largest component of the overall delay between onset of symptoms and receipt of therapy.$^{16}$ No study has examined the effect of marital status on patients' delay, and only a few small studies have examined predictors of this component of delay by sex..$^{17,18}$

We examined the effect of marital status, a social factor, on the time from onset of chest pain to arrival in an emergency department or hospital, in a population-based cohort of patients with acute myocardial infarction. We hypothesized that being married or in a common-law relationship would be associated with less delay, because we surmised that a spouse would encourage earlier pursuit of medical care, either directly or indirectly (i.e., even if the spouse was not physically present during the symptoms, his or her existence might spur the patient to seek care earlier). We hypothesized that wives would be more likely than husbands to assume the caregiver role and 
that the beneficial effect of marriage would therefore be stronger among men than among women.

\section{Methods}

\section{Study design}

For this retrospective cohort study, we obtained ethics approval from Sunnybrook Health Sciences Centre and from all participating hospitals.

\section{Setting and data sources}

The Enhanced Feedback for Effective Cardiac Treatment (EFFECT) study involved a populationbased sample of patients with acute myocardial infarction from the province of Ontario, Canada, who sought care from April 2004 to March 2005. ${ }^{19}$ Ontario is Canada's largest and most ethnically diverse province, with a population of 13 million..$^{20}$ During the follow-up phase of the EFFECT study, used for the analysis reported here, clinical data were gathered from chart reviews of 7746 patients with acute myocardial infarction seen in 82 hospital corporations in Ontario. To be eligible, a hospital had to have treated more than 15 patients with acute myocardial infarction per year, and all but 4 of the 86 eligible hospital corporations in Ontario completed this second phase. Trained nurse abstractors performed the chart reviews on a population-based, random sample of the patients who had been treated for acute myocardial infarction at each hospital, according to prespecified rules for chart review. Our assessment of inter-rater reliability for the nurse abstractors demonstrated high reliability for all of the indicators assessed in the EFFECT study. ${ }^{21,22}$

\section{Selection of participants}

The EFFECT study included Ontario residents 20 to 105 years of age with a valid Ontario Health Card number who had been admitted to an acute care hospital with a most responsible diagnosis of acute myocardial infarction. ${ }^{19} \mathrm{We}$ identified patients from the Discharge Abstract Database of the Canadian Institute for Health Information, which contains information about all hospital admissions in Ontario, and we ver ified each case using the patient's hospital chart. We confirmed the diagnosis using established criteria: positive cardiac enzymes in conjunction with either electrocardiographic changes or symptoms consistent with acute myocardial infarction. ${ }^{23}$ We excluded patients whose myocardial infarction was an in-hospital complication. We also excluded patients who did not experience chest pain in association with the acute myocardial infarction, patients who were sent to the emergency department directly from the care of a physician or another hospital, and those who came from a long-term care facility. We counted patients who were transferred to a second site only once, on the basis of arrival time at the first site.

\section{Outcome measures}

The primary outcome measure was delayed time to presentation to a hospital after the onset of chest pain. We used several analyses to determine this outcome. The primary analysis was based on presentation to hospital more than six hours after the onset of chest pain, both overall and then stratified by sex. The timeframe of six hours was chosen for consistency with the previous literature ${ }^{24-26}$ and because we sought a patient-oriented definition of delay, given that this delay is under the patient's control. To a patient, whose chest pain may occur intermittently over several hours, it may not seem unreasonable to wait several hours to see if it "goes away." Secondary analyses were based on presentation more than 2 hours, more than 6 hours and more than 12 hours after onset of chest pain, both overall and stratified by sex, as well as a continuous measure of time since onset of chest pain. The continuous measure of time was chosen for secondary analysis because of the smaller sample size of patients for whom the exact time of onset of chest pain was known.

We defined the time of onset of chest pain as the date and time when the chest pain began, as reported by the patient and recorded in the chart. If a specific time of onset was not documented, and the duration of pain was recorded instead, we categorized the duration as 0 to 2 hours, more than 2 to 6 hours, more than 6 to 12 hours or

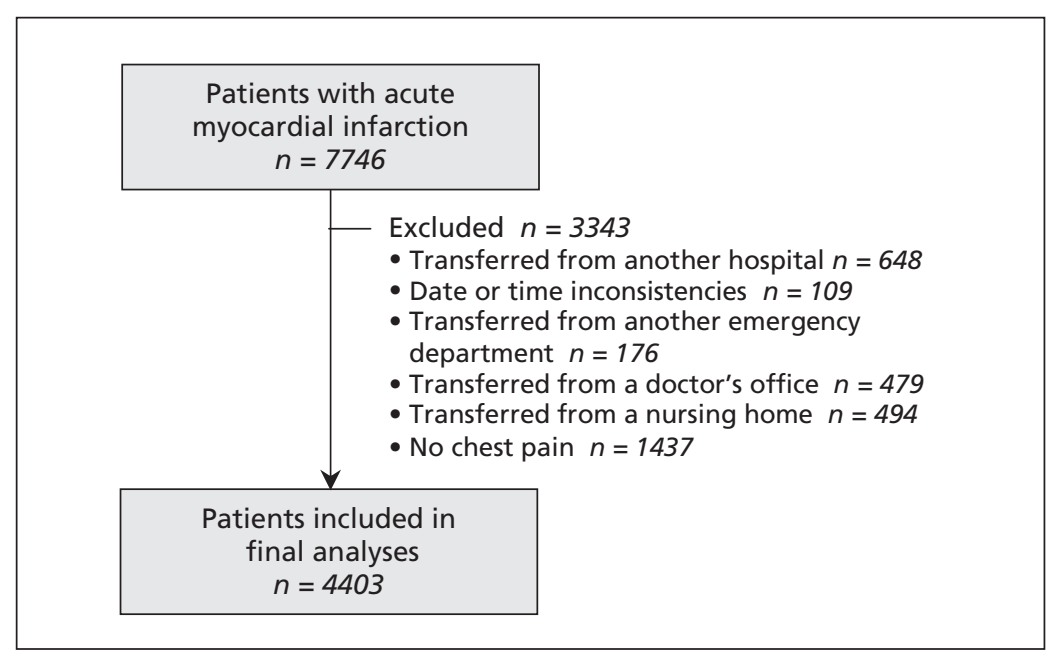

Figure 1: Flow chart for 7746 patients with acute myocardial infarction in the Enhanced Feedback for Effective Cardiac Treatment study and the $\mathbf{4 4 0 3}$ patients included in the current study, after application of exclusion criteria. The final number of patients in the analyses includes 75 patients who bypassed the emergency department and went straight to the cardiac catheterization laboratory, the cardiac care unit or the hospital ward. 
more than 12 hours. If the chest pain could not be categorized and a specific time was not assigned, we considered data for the duration of chest pain to be missing. We counted and recorded chest pain of any quality or nature.

In the EFFECT study, we defined the time of arrival as the time when the patient was seen by a triage nurse in the emergency department, which in Canada occurs before patient registration, as it does in the United States. ${ }^{27}$ If the triage time was not available, we used the registration time. If the patient bypassed the emergency department (going directly to a ward, cardiac care unit or catheterization laboratory), we used the time of arrival at the hospital.

\section{Definitions of variables}

We obtained marital status from the hospital chart. In Ontario, collection of marital status is mandatory for all patients seen in an emergency department. The registration clerk makes a standard inquiry about marital status during registration, either to the patient (if conscious) or to an accompanying individual. To be consistent with

\begin{tabular}{|c|c|c|c|c|c|c|}
\hline \multirow[b]{2}{*}{ Characteristic* } & \multicolumn{4}{|c|}{$\begin{array}{l}\text { Duration between pain onset and presentation; } \\
\text { no. }(\%) \text { of patients†‡ }\end{array}$} & \multirow[b]{2}{*}{$\begin{array}{c}\text { Total } \\
n=4403\end{array}$} & \multirow[b]{2}{*}{$p$ value } \\
\hline & $\begin{array}{l}0 \text { to } 2 \mathrm{~h} \\
n=2037\end{array}$ & $\begin{array}{c}>2 \text { to } 6 \mathrm{~h} \\
n=1203\end{array}$ & $\begin{array}{c}>6 \text { to } 12 \mathrm{~h} \\
n=437\end{array}$ & $\begin{array}{l}>12 \mathrm{~h} \\
n=726\end{array}$ & & \\
\hline \multicolumn{7}{|l|}{ Marital status } \\
\hline Single & $111(40.1)$ & 77 (27.8) & 33 (11.9) & $56(20.2)$ & 277 & $<0.001$ \\
\hline Married or common law & $1493(48.5)$ & $824(26.8)$ & $287 \quad(9.3)$ & $475(15.4)$ & 3079 & \\
\hline Divorced or separated & $125(45.3)$ & $64(23.2)$ & $34(12.3)$ & $53(19.2)$ & 276 & \\
\hline Widowed & 308 (39.9) & $238(30.9)$ & $83(10.8)$ & $142(18.4)$ & 771 & \\
\hline \multicolumn{7}{|l|}{ Age } \\
\hline Mean (SD) & $65.8(13.7)$ & $68.4(13.2)$ & $69.9(13.6)$ & $68.2(13.6)$ & $67.3(13.6)$ & $<0.001$ \\
\hline \multicolumn{7}{|l|}{ Sex } \\
\hline Female & $643(43.3)$ & $425(28.6)$ & $153(10.3)$ & 265 (17.8) & 1486 & 0.037 \\
\hline Male & $1394(47.8)$ & $778(26.7)$ & $284 \quad(9.7)$ & $461 \quad(15.8)$ & 2917 & \\
\hline \multicolumn{7}{|l|}{ Ethnic origin } \\
\hline Chinese & $29(46.8)$ & $19(30.6)$ & $4 \quad(6.5)$ & $10(16.1)$ & 62 & \\
\hline South Asian & $88(51.8)$ & $49(28.8)$ & $15 \quad(8.8)$ & $18(10.6)$ & 170 & \\
\hline Other & $945(42.3)$ & $623(27.9)$ & $237(10.6)$ & $428(19.2)$ & 2233 & 0.39 \\
\hline \multicolumn{7}{|l|}{ Income quintile } \\
\hline First (lowest) & 427 (43.4) & $274(27.9)$ & $106(10.8)$ & $176(17.9)$ & 983 & 0.08 \\
\hline Second & $426(46.4)$ & $235(25.6)$ & $102(11.1)$ & $155(16.9)$ & 918 & \\
\hline Third & $376(44.1)$ & $235(27.5)$ & $94(11.0)$ & $148(17.4)$ & 853 & \\
\hline Fourth & $426(49.6)$ & $235(27.4)$ & $69 \quad(8.0)$ & $129(15.0)$ & 859 & \\
\hline Fifth (highest) & $378(48.8)$ & $217(28.0)$ & $65 \quad(8.4)$ & $114(14.7)$ & 774 & \\
\hline \multicolumn{7}{|l|}{ Living arrangement } \\
\hline Alone & $360(41.0)$ & $256(29.2)$ & $100(11.4)$ & $162(18.5)$ & 878 & 0.023 \\
\hline With someone & $1650(47.7)$ & $925(26.7)$ & $331 \quad(9.6)$ & $552(16.0)$ & 3458 & \\
\hline \multicolumn{7}{|l|}{ Ambulance called } \\
\hline No & $1040(40.5)$ & $685(26.7)$ & $293(11.4)$ & $548(21.4)$ & 2566 & $<0.001$ \\
\hline Yes & $997(54.3)$ & $518(28.2)$ & $144 \quad(7.8)$ & $178 \quad(9.7)$ & 1837 & \\
\hline \multicolumn{7}{|l|}{ Shortness of breath } \\
\hline No & $1422(47.4)$ & $809(27.0)$ & $290 \quad(9.7)$ & 478 (15.9) & 2999 & 0.10 \\
\hline Yes & $601(43.5)$ & $391(28.3)$ & $145(10.5)$ & $245(17.7)$ & 1382 & \\
\hline \multicolumn{7}{|l|}{ Previous AMI } \\
\hline No & $1511(46.3)$ & $881(27.0)$ & $309 \quad(9.5)$ & $563(17.2)$ & 3264 & 0.13 \\
\hline Yes & $502(46.0)$ & $306(28.0)$ & $125(11.5)$ & 158 (14.5) & 1091 & \\
\hline
\end{tabular}


previous published research, we categorized marital status as single, married or common law (herein referred to as "married"), divorced or separated (herein referred to as "divorced") and widowed. ${ }^{7,28}$

In our regression models, we accounted for 16 potential confounders, covering a variety of patient demographic characteristics, clinical features, relevant medical history and contextual factors. Collection of information about a patient's living arrangement is mandatory for patients seen in emergency departments in Ontario. The registration clerk asks the patient if he or she is living with someone else, but no further instructions are provided for collection of this information. Therefore, "living with someone" may refer to anyone who lives in the same dwelling. We recorded ethnicity if it had been documented in the patient's chart. For patients for whom ethnicity was not recorded, we analyzed the patient's surname using a database of surnames for visible minorities. This database has been used previously to assign Chinese and South Asian ethnicities. ${ }^{29}$ Those whose surnames were deemed to be either Chinese or South Asian were recorded as being

Table 1: Baseline characteristics of the study cohort of 4403 patients with acute myocardial infarction (AMI), by duration of time between onset of chest pain and presentation to the emergency department (part 2 of 2)

\begin{tabular}{|c|c|c|c|c|c|c|}
\hline \multirow[b]{2}{*}{ Characteristic* } & \multicolumn{4}{|c|}{$\begin{array}{l}\text { Duration between pain onset and presentation; } \\
\text { no. }(\%) \text { of patients†‡ }\end{array}$} & \multirow[b]{2}{*}{$\begin{array}{c}\text { Total } \\
n=4403\end{array}$} & \multirow[b]{2}{*}{$p$ value } \\
\hline & $\begin{array}{l}0 \text { to } 2 \mathrm{~h} \\
n=2037\end{array}$ & $\begin{array}{l}>2 \text { to } 6 \mathrm{~h} \\
n=1203\end{array}$ & $\begin{array}{l}>6 \text { to } 12 \mathrm{~h} \\
\quad n=437\end{array}$ & $\begin{array}{l}>12 h \\
n=726\end{array}$ & & \\
\hline \multicolumn{7}{|l|}{ Previous $\mathrm{PCl}$ or CABG } \\
\hline No & $1729(46.1)$ & $1023(27.3)$ & $360 \quad(9.6)$ & $640(17.1)$ & 3752 & 0.046 \\
\hline Yes & $308(47.3)$ & $180(27.6)$ & 77 (11.8) & $86(13.2)$ & 651 & \\
\hline \multicolumn{7}{|l|}{ History of hypertension } \\
\hline No & $866(48.5)$ & $478(26.7)$ & $165 \quad(9.2)$ & $278(15.6)$ & 1787 & 0.06 \\
\hline Yes & $1155(44.5)$ & $723(27.9)$ & $270(10.4)$ & $446(17.2)$ & 2594 & \\
\hline \multicolumn{7}{|l|}{ History of diabetes mellitus } \\
\hline No & $1536(47.6)$ & $862(26.7)$ & $315 \quad(9.8)$ & $517(16.0)$ & 3230 & 0.029 \\
\hline Yes & $496(42.5)$ & $341(29.2)$ & $122(10.4)$ & 209 (17.9) & 1168 & \\
\hline \multicolumn{7}{|l|}{ History of dyslipidemia } \\
\hline No & $981(43.9)$ & $625(27.9)$ & $220 \quad(9.8)$ & 411 (18.4) & 2237 & 0.01 \\
\hline Yes & $1023(48.9)$ & $556(26.6)$ & $210(10.0)$ & 305 (14.6) & 2094 & \\
\hline \multicolumn{7}{|l|}{ History of smoking } \\
\hline Current & $612(48.3)$ & $330(26.0)$ & $117 \quad(9.2)$ & $208(16.4)$ & 1267 & 0.008 \\
\hline Former & $611(48.5)$ & $358(28.4)$ & $116 \quad(9.2)$ & $175(13.9)$ & 1260 & \\
\hline Never & $652(43.5)$ & $419(28.0)$ & $154(10.3)$ & $274(18.3)$ & 1499 & \\
\hline Unknown & $162(43.0)$ & $96(25.5)$ & $50(13.3)$ & $69(18.3)$ & 377 & \\
\hline \multicolumn{7}{|l|}{ History of depression } \\
\hline No & $1848(46.3)$ & $1106(27.7)$ & $387 \quad(9.7)$ & $653(16.3)$ & 3994 & 0.08 \\
\hline Yes & $165(44.8)$ & 87 (23.6) & $47(12.8)$ & $69(18.8)$ & 368 & \\
\hline \multicolumn{7}{|l|}{ Arrival day } \\
\hline Weekday & $1437(46.5)$ & $845(27.3)$ & $305 \quad(9.9)$ & $503(16.3)$ & 3090 & \\
\hline Weekend & $599(45.7)$ & $358(27.3)$ & $132(10.1)$ & $223(17.0)$ & 1312 & \\
\hline \multicolumn{7}{|l|}{ Arrival time } \\
\hline Daytime (8:01 am to $4 \mathrm{pm})$ & $795(42.9)$ & $466(25.2)$ & $202(10.9)$ & $389(21.0)$ & 1852 & $<0.001$ \\
\hline Evening (4:01 pm to midnight) & $542(49.0)$ & $299(27.0)$ & $91 \quad(8.2)$ & $174(15.7)$ & 1106 & \\
\hline Night (12:01 am to $8 \mathrm{am})$ & $699(48.4)$ & $438(30.3)$ & $144(10.0)$ & $163(11.3)$ & 1444 & \\
\hline \multicolumn{7}{|c|}{$\begin{array}{l}\text { Note: } \mathrm{CABG}=\text { coronary artery bypass graft, } \mathrm{PCl}=\text { percutaneous coronary intervention, } \mathrm{SD}=\text { standard deviation. } \\
\text { *For some variables, data were missing for some patients, as follows: for ethnic origin, } 1938 \text { patients; for income quintile, } 16 \text { patients; for living arrangement, } 67 \\
\text { patients; for shortness of breath, } 22 \text { patients; for previous AMI, } 48 \text { patients; for history of hypertension, } 22 \text { patients; for history of diabetes mellitus, } 5 \text { patients; for } \\
\text { history of dyslipidemia, } 72 \text { patients; for history of depression, } 41 \text { patients; for arrival day, } 1 \text { patient; for arrival time, } 1 \text { patient. } \\
\text { tExcept as indicated otherwise. } \\
\text { fPercentages are calculated across rows, with the denominator for each row being the value appearing in the "Total" column. }\end{array}$} \\
\hline
\end{tabular}


from these ethnic groups. Socioeconomic status was based on median neighbourhood household income and was categorized in quintiles, from lowest (income quintile 1) to highest (income quintile 5). ${ }^{20}$

\section{Statistical analyses}

To determine the independent effect of marital status on delayed presentation (i.e., more than six hours from onset of pain), we used multivariable logistic regression modelling. To address whether the effect of marital status differed by sex, we fit

Table 2: Adjusted odds of delayed presentation to the emergency department (i.e., presentation more than six hours after onset of chest pain) among 4403 patients with acute myocardial infarction (AMI)

\begin{tabular}{|c|c|c|}
\hline Predictor variable & $\begin{array}{l}\text { Adjusted OR } \\
\quad(95 \% \mathrm{Cl})\end{array}$ & $p$ value \\
\hline \multicolumn{3}{|l|}{ Marital status (reference $=$ single) } \\
\hline Married or common law & $0.46(0.30-0.71)$ & $<0.001$ \\
\hline Separated or divorced & $0.90(0.53-1.52)$ & 0.69 \\
\hline Widowed & $0.65(0.41-1.03)$ & 0.07 \\
\hline Age (per decade increase) & $1.20(1.15-1.26)$ & $<0.001$ \\
\hline Male sex & $1.05(0.84-1.32)$ & 0.67 \\
\hline \multicolumn{3}{|l|}{ Ethnic origin (reference = general) } \\
\hline Chinese & $0.61(0.31-1.19)$ & 0.15 \\
\hline South Asian & $0.50(0.32-0.78)$ & 0.002 \\
\hline \multicolumn{3}{|c|}{$\begin{array}{l}\text { Income quintile (reference = quintile } 1 \\
\text { [lowest]) }\end{array}$} \\
\hline Income quintile 2 & $0.92(0.70-1.20)$ & 0.53 \\
\hline Income quintile 3 & $0.97(0.73-1.28)$ & 0.81 \\
\hline Income quintile 4 & $0.61(0.45-0.82)$ & 0.001 \\
\hline Income quintile 5 & $0.66(0.49-0.89)$ & 0.006 \\
\hline Living with someone & $1.47(1.06-2.04)$ & 0.020 \\
\hline Called an ambulance & $0.42(0.34-0.51)$ & 0.001 \\
\hline Shortness of breath & $1.14(0.93-1.39)$ & 0.21 \\
\hline Previous AMI & $1.02(0.80-1.31)$ & 0.87 \\
\hline Previous $\mathrm{PCl}$ or $\mathrm{CABG}$ & $0.91(0.67-1.23)$ & 0.54 \\
\hline History of hypertension & $1.19(0.97-1.46)$ & 0.10 \\
\hline History of diabetes mellitus & $1.19(0.96-1.48)$ & 0.11 \\
\hline History of dyslipidemia & $0.84(0.68-1.03)$ & 0.09 \\
\hline \multicolumn{3}{|l|}{ Smoker (reference = current smoker) } \\
\hline Never & $1.01(0.78-1.31)$ & 0.94 \\
\hline Former & $0.85(0.65-1.12)$ & 0.25 \\
\hline History of depression & $1.61(1.18-2.20)$ & 0.003 \\
\hline Weekend arrival & $1.15(0.95-1.41)$ & 0.16 \\
\hline \multicolumn{3}{|l|}{$\begin{array}{l}\text { Arrival time (reference }=\text { daytime } \\
[8: 01 \text { am to } 4 \mathrm{pm}])\end{array}$} \\
\hline Evening (4:01 pm to midnight) & $0.78(0.62-0.97)$ & 0.030 \\
\hline Night (12:01 am to $8 \mathrm{am})$ & $0.61(0.49-0.76)$ & $<0.001$ \\
\hline
\end{tabular}

the same logistic regression model for men and women separately. The variables were chosen a priori, on the basis of clinical significance, and all variables were included in the models. A stepwise procedure was not used, because such an approach can produce biased estimates. ${ }^{32}$ In the secondary analysis, we used proportional odds logistic regression to estimate the effect of marital status on the odds of delayed presentation at any of the three levels of delay. This produced the odds of married people (relative to single people) presenting late, regardless of the cut-off chosen (2, 6 or 12 hours), and allowed the ordinal character of the data to be retained. We then fit the same proportional odds logistic regression model for men and women separately. Finally, we used quantile regression ${ }^{30}$ to determine the independent effect of marital status on the median delay to presentation, in minutes. Quantile regression is appropriate when data are rightskewed. ${ }^{31}$ Unlike linear regression, in which the mean value of the outcome variable is regressed on a set of covariates, quantile regression allows modelling of any quantile of the outcome variable, including the median, on a set of covariates. We used bootstrap resampling to estimate standard errors and $95 \%$ confidence intervals (CIs). Given the smaller sample size for this analysis, the power was insufficient to fit the quantile regression model separately by sex. We examined all models for collinearity (including marital status and living arrangement) and goodness of fit. Adjusted odds ratios (ORs) greater than 1.0 represent an increased risk of delayed presentation, whereas adjusted ORs less than 1.0 represent a decreased risk of delayed presentation.

\section{Results}

Of the 7746 patients with confirmed acute myocardial infarction who were initially identified in the EFFECT study, 3343 met our exclusion criteria, which left 4403 patients in the final study cohort (Figure 1). The mean age was 67.3 years, and $1486(33.7 \%)$ of participants were women (Table 1). The 30-day mortality rate was $6.9 \%$ (95\% CI 6.1\%-7.6\%).

For the 3840 patients for whom exact times from onset of chest pain to presentation at an emergency department or hospital were available, the median time was 2.0 (interquartile range [IQR] 1.0-4.6) hours. Categorized by marital status, the median times were 2.0 (IQR 1.0-4.3) hours for married patients, 2.5 (IQR 1.1-6.0) hours for single patients, 2.0 (IQR 1.0$5.5)$ hours for divorced patients and 2.5 (IQR 1.3-5.0) hours for widowed patients $(p<0.001)$. The adjusted odds of a delayed presentation 
(more than six hours after onset of pain) were lower for married patients (OR 0.46, 95\% CI $0.30-0.71, p<0.001)$ relative to single patients (Table 2). Other significant predictors of delayed presentation were older age, low socioeconomic status, living with another person, not calling an ambulance, chart-documented history of depression and daytime arrival in the emergency department; ethnic background was also a significant determining factor.

When we analyzed the data separately for men and women, we found a significant relation for men between being married and earlier presentation (i.e., no more than six hours after onset of pain) (OR $0.35,95 \%$ CI $0.21-0.59, p<$ $0.001)$. However, this relation was not significant for women (OR 1.36, 95\% CI 0.49-3.73, $p=0.55)$. Among men, other factors that reduced the odds of a delay in presentation included South Asian ethnicity, calling an ambulance and night-time presentation, whereas older age was associated with delayed presentation (Figure 2). Among women, being divorced was associated with increased odds of delayed presentation, relative to being single, as were older age and a charted history of depression. In contrast, calling an ambulance and higher income level were associated with lower odds of delayed presentation among women (Figure 3).

For all patients, being married was associated with reduced odds of presentation after 2, 6 or 12 hours of delay (OR $0.45,95 \%$ CI $0.31-0.64, p<$ $0.001)$, relative to being single. For men, the same analysis resulted in an OR of 0.39 (95\% CI $0.25-0.62, p<0.001)$, whereas for women the relation was not significant (OR $0.72,95 \% \mathrm{CI}$ $0.35-1.48, p=0.37$ ).

For patients with a discrete duration of the time between onset of chest pain and presentation to the emergency department, there was a trend toward a shorter time to presentation among married patients. For these patients, the adjusted time to presentation was 30.4 minutes less (95\% CI $62.6 \mathrm{~min}$ less to $1.8 \mathrm{~min}$ more) than the time for their single counterparts (Table 3).

\section{Characteristic}

Married or common law

Separated or divorced

Widowed

Age*

High income quintile

Chinese ethnicity

South Asian ethnicity

Lives with someone

Ambulance called

Shortness of breath

Previous AMI

Previous $\mathrm{PCl}$ or $\mathrm{CABG}$

History of hypertension

History of diabetes

History of dyslipidemia

Never smoked

Former smoker

History of depression

Weekend arrival

Evening arrival

Night arrival
OR $(95 \% \mathrm{CI})$

$0.35(0.21-0.59)$

$0.47(0.24-0.92)$

$0.60(0.32-1.12)$

1.18 (1.11-1.24)

$0.76(0.52-1.11)$

$0.77(0.36-1.64)$

$0.40(0.22-0.72)$

$1.59(0.96-2.63)$

$0.41(0.31-0.53)$

$1.08(0.83-1.40)$

0.99 (0.73-1.35)

$0.90(0.62-1.29)$

1.19 (0.92-1.53)

1.24 (0.95-1.63)

0.83 (0.65-1.07)

$0.93(0.67-1.28)$

$0.86(0.62-1.19)$

$1.45(0.93-2.27)$

$1.13(0.88-1.45)$

$0.82(0.61-1.09)$

$0.56(0.43-0.74)$

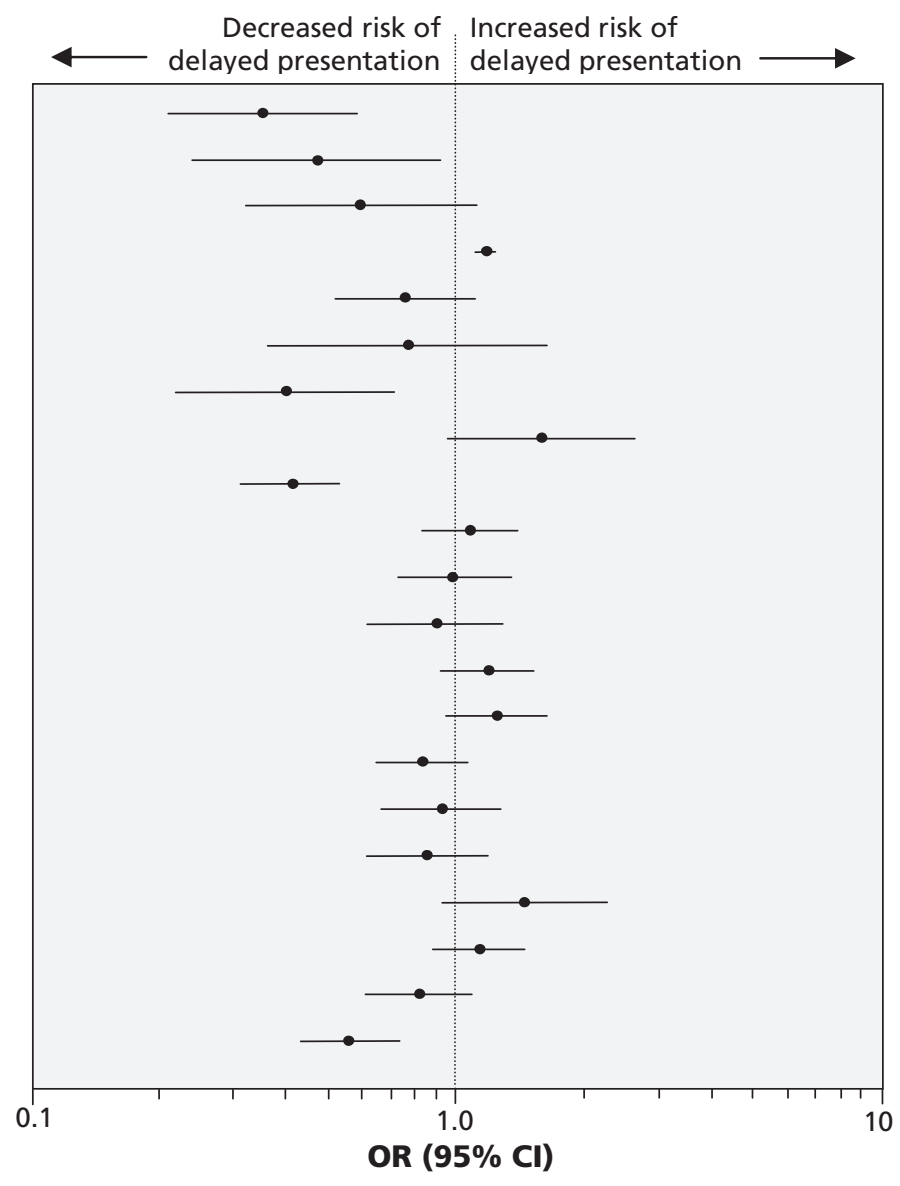

Figure 2: Adjusted odds, with 95\% confidence intervals (Cls), of a delayed presentation (more than six hours from onset of chest pain) in men with acute myocardial infarction (AMI). *For every decade increase in age. Note: CABG = coronary artery bypass graft, OR = odds ratio, $\mathrm{PCl}=$ percutaneous coronary intervention. 


\section{Interpretation}

In this population-based study, patients who were experiencing chest pain due to acute myocardial infarction presented to an emergency department or hospital earlier if they were married or in a common-law relationship, relative to those who were single. Delays measured in minutes are known to increase the risk of death in some cases of acute myocardial infarction. ${ }^{8,9}$ In addition, previous studies have shown a relation between marital status and overall mortality, 3,4 including mortality from cardiovascular diseases. ${ }^{7}$ Thus, earlier presentation for care among married persons with acute myocardial infarction may partly explain the mortality benefit associated with being married. At the patient level, among patients with an exact time of onset of chest pain, the adjusted time saved was a remarkable half-hour. Among all the factors that had an effect in the primary outcome model, only calling an ambulance had a greater influence on the time to presentation. Because cardio- vascular disease is the most frequent cause of death in Canada and the Western world, ${ }^{33}$ the benefit at the population level is substantial.

Consistent with our a priori hypothesis, the earlier presentation associated with being married was more pronounced for men than for women. The stratified analysis demonstrated that marriage conferred a significant reduction in delays for men, which was not the case for women. We surmise that, in general, women may be more likely than men to take the role of caregiver and to advise their spouses to seek early medical assessment.

It is well known that lack of chest pain is a major source of delay in seeking treatment among patients with acute myocardial infarction. ${ }^{13,24}$ We focused specifically on patients who had this typical symptom of acute myocardial infarction, to investigate why these particular patients may delay seeking care. Despite numerous studies on the topic of patient-caused delays, ${ }^{13,24,25}$ only one small study has specifically

\section{Characteristic \\ Married or common law \\ Separated or divorced \\ Widowed \\ Age*}

Highest income quintile

Chinese ethnicity

South Asian ethnicity

Lives with someone

Ambulance called

Shortness of breath

Previous AMI

Previous $\mathrm{PCl}$ or $\mathrm{CABG}$

History of hypertension

History of diabetes

History of dyslipidemia

Never smoked

Former smoker

History of depression

Weekend arrival

Evening arrival

Night arrival
OR (95\% Cl)

$1.36(0.49-3.73)$

4.02 (1.34-12.07)

$1.49(0.55-3.99)$

$1.31(1.201-1.43)$

$0.51(0.30-0.88)$

$0.31(0.076-1.41)$

$0.74(0.37-1.49)$

$1.27(0.81-2.01)$

$0.43(0.30-0.60)$

$1.29(0.93-1.78)$

$1.11(0.72-1.71)$

$1.02(0.59-1.78)$

$1.22(0.84-1.78)$

$1.16(0.81-1.67)$

$0.83(0.59-1.20)$

$1.17(0.72-1.90)$

0.87 (0.50-1.49)

$1.90(1.22-2.98)$

$1.15(0.81-1.61)$

0.68 (0.46-1.01)

$0.69(0.47-1.01)$
Decreased risk of Increased risk of

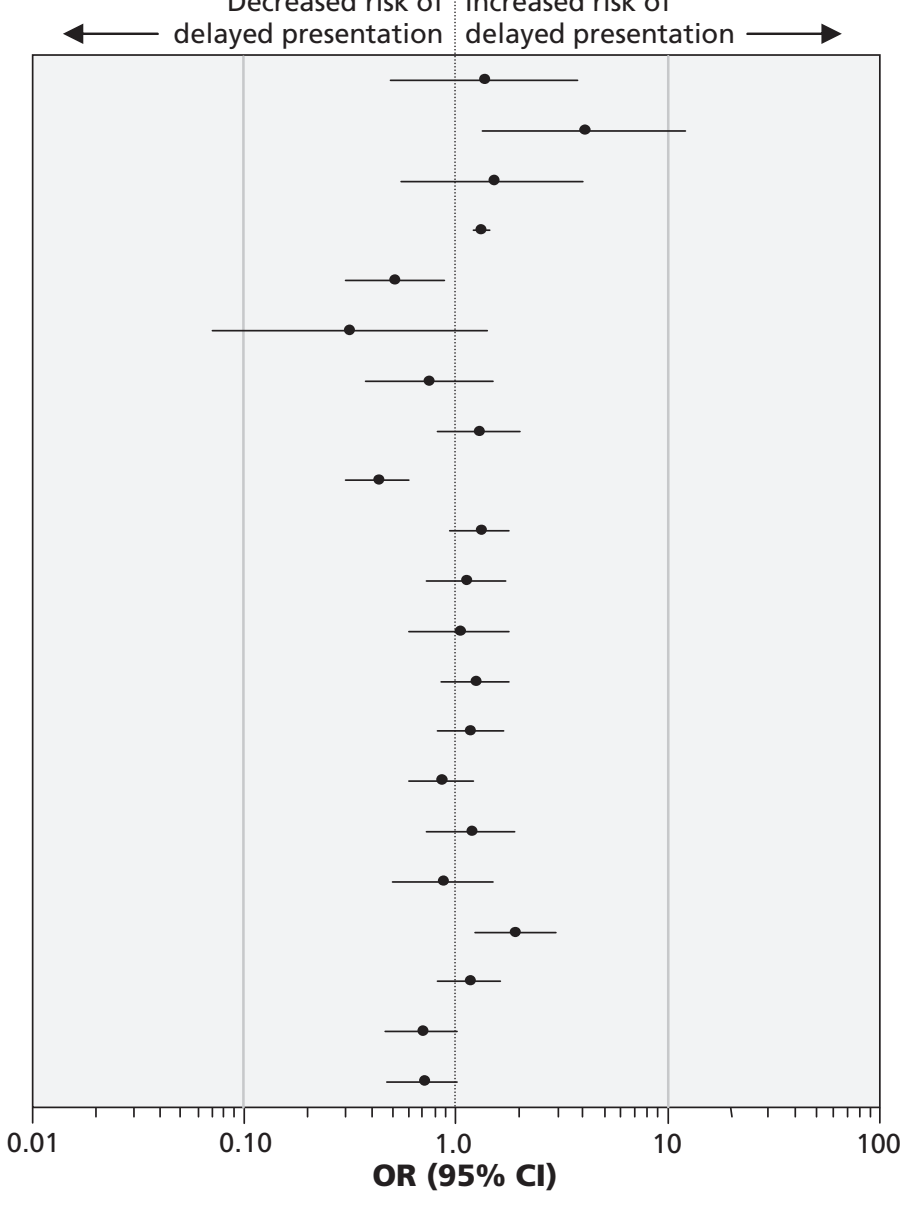

Figure 3: Adjusted odds, with $95 \%$ confidence intervals (Cls), of a delayed presentation (more than six hours from onset of chest pain) in women with acute myocardial infarction (AMI). *For every decade increase in age. Note: CABG = coronary artery bypass graft, OR = odds ratio, $\mathrm{PCl}=$ percutaneous coronary intervention. 
examined patients who have chest pain in association with acute myocardial infarction. ${ }^{34}$ The predictors of patient-caused delay in our study were similar to those reported in previous studies of patients with acute myocardial infarction, who may or may not have had chest pain. ${ }^{12,24,26,35}$ In other studies, older patients were more likely to present late, ${ }^{12,13,24,25,35}$ but this was thought to be due in part to atypical symptoms, which are common in elderly people. ${ }^{36}$ In our study, older age predicted delayed presentation, despite the fact that all patients were experiencing the typical symptom of chest pain. Thus, it is apparently not just atypical symptoms that lead to patientcaused delays among elderly people.

In contrast to previous studies, ${ }^{24,25,35}$ female sex was not associated with delayed presentation in this study. This result was likely due to our inclusion of only patients who had chest pain, which differs from the inclusion criteria for previous studies. Because women are more likely to have atypical symptoms, ${ }^{36,37}$ the association of delayed presentation with female sex may disappear once women without chest pain are excluded. As well, several studies have noted a diminishing difference between the sexes in terms of patient-caused delays over the years, ${ }^{13,38}$ which could also account, at least in part, for the lack of delay in presentation for women in our study.

Few studies have assessed predictors of patient-caused delay by sex. In one study, older women and women with a history of acute myocardial infarction were more likely to delay seeking care. ${ }^{18}$ This finding was dissimilar to the results of our study, but that earlier study was limited to 96 female patients. ${ }^{18}$ In another study, single women were more likely to delay than married women, but again, the sample size was limited (61 patients). ${ }^{17}$ In our study, factors that were significant for women were age, ${ }^{18,25}$ calling an ambulance and evening arrival, ${ }^{12,24}$ consistent with previous studies involving patients of both sexes. Interestingly, in our study women in the highest socioeconomic bracket were less likely to delay seeking care relative to those in the lowest income bracket, an association not found for men. Lower socioeconomic status could be associated with less education about heart disease among women in particular. As such, these patients may represent an important target group for future educational campaigns. Having a chartdocumented history of depression was associated with increased delays among women. Depression may result in a lack of motivation to seek care. Given that a history of depression is common in patients with acute myocardial infarction, ${ }^{39,40}$ these patients may need reinforcement to seek prompt medical attention for chest pain.

\section{Limitations}

Missing data represent a limitation of retrospective data collection, as was used for this study. However, rigorous training of the nurse chart abstractors, use of standardized data collection instruments and evaluation of inter-rater reliability should limit bias in our results. ${ }^{13}$ Marital status was not validated through an external source. Collection of these data are mandatory in Ontario emergency departments, but if the patient had a decreased level of consciousness and was unaccompanied on arrival in the emergency department, this information would not

Table 3: Quantile regression analyses for 3967 patients with acute myocardial infarction (AMI) who had time recorded from onset of chest pain to presentation at emergency department

\begin{tabular}{|c|c|c|}
\hline Predictor variable & $\begin{array}{l}\text { Parameter estimate, * } \\
\min (95 \% \mathrm{Cl})\end{array}$ & $p$ value \\
\hline \multicolumn{3}{|l|}{ Marital status (reference $=$ single) } \\
\hline Married or common law & $-30.4(-62.6$ to 1.8$)$ & 0.06 \\
\hline Separated or divorced & $-25.0(-60.5$ to 10.6$)$ & 0.17 \\
\hline Widowed & $-27.7(-63.2$ to 7.8$)$ & 0.13 \\
\hline Age, per decade increase & $13.8 \quad$ (9.0 to 18.8$)$ & $<0.001$ \\
\hline Male sex & $-2.9 \quad(-9.4$ to 15.1$)$ & 0.64 \\
\hline \multicolumn{3}{|l|}{ Ethnic origin (reference $=$ general) } \\
\hline Chinese & $-37.3(-47.9$ to 22.3$)$ & 0.48 \\
\hline South Asian & $-5.6(-29.3$ to 18.0$)$ & 0.64 \\
\hline \multicolumn{3}{|l|}{$\begin{array}{l}\text { Income quintile (reference = } \\
\text { quintile } 1 \text { [lowest]) }\end{array}$} \\
\hline Income quintile 2 & $-11.6(-27.1$ to 4.0$)$ & 0.15 \\
\hline Income quintile 3 & $5.9 \quad(-9.2$ to 20.9$)$ & 0.45 \\
\hline Income quintile 4 & -13.6 ( -28.0 to 0.8$)$ & 0.06 \\
\hline Income quintile 5 & $-18.0(-32.0$ to -4.1$)$ & 0.01 \\
\hline Living with someone & 0.6 (-20.8 to 22.0$)$ & $>0.99$ \\
\hline Ambulance called & $-47.2(-57.8$ to -36.5$)$ & $<0.001$ \\
\hline Shortness of breath & $5.3 \quad(-5.5$ to 16.1$)$ & 0.34 \\
\hline Previous AMI & $1.5(-13.7$ to 16.8$)$ & 0.84 \\
\hline Previous $\mathrm{PCl}$ or $\mathrm{CABG}$ & 5.5 (-11.1 to 22.2$)$ & 0.52 \\
\hline History of hypertension & $8.7 \quad(-1.1$ to 18.4$)$ & 0.08 \\
\hline History of diabetes mellitus & $17.1 \quad$ (1.9 to 32.4$)$ & 0.03 \\
\hline History of dyslipidemia & $-11.4(-21.2$ to -1.6$)$ & 0.02 \\
\hline Never smoked & $6.4 \quad(-6.0$ to 18.9$)$ & 0.31 \\
\hline History of depression & $12.1 \quad(-4.6$ to 28.7$)$ & 0.15 \\
\hline Weekend arrival & $0.4(-10.5$ to 11.4$)$ & 0.94 \\
\hline \multicolumn{3}{|l|}{$\begin{array}{l}\text { Arrival time }(\text { reference = morning } \\
[8: 01 \mathrm{am} \text { to } 4 \mathrm{pm}])\end{array}$} \\
\hline Evening (4:01 pm to midnight) & $-13.9(-26.1$ to -1.6$)$ & 0.03 \\
\hline Night (12:01 am to $8 \mathrm{am})$ & $-4.8(-16.5$ to 6.8$)$ & 0.42 \\
\hline \multicolumn{3}{|c|}{$\begin{array}{l}\text { Note: } \mathrm{CABG}=\text { coronary artery bypass graft, } \mathrm{Cl}=\text { confidence interval, } \mathrm{PCl}=\text { percutaneous } \\
\text { coronary intervention. } \\
\text { *Parameter estimates represent the adjusted delay, in minutes, for each covariate, where a } \\
\text { positive value indicates delayed presentation and a negative value indicates earlier } \\
\text { presentation. }\end{array}$} \\
\hline
\end{tabular}


have been collected. As such, the sickest patients were probably excluded from our study, and our results may not apply to them. Also, we did not include anyone with missing data on the independent variable of interest, marital status. We did not collect information on educational status, although socioeconomic status likely accounts for some of its contribution. We did not account for distance from the patient's dwelling to the hospital; however, long distances would have applied for a relatively small proportion of patients.

\section{Conclusions}

Among men, married or common law status was strongly associated with earlier health-seeking behaviour in the setting of acute myocardial infarction. Among women, married or common law status was not associated with a similar reduction in delay before seeking medical attention. Earlier attainment of medical care may be one reason why married men have a lower risk of cardiovascular mortality than their single counterparts. Awareness of the differences in reasons for delay by sex could facilitate the development of targeted public health campaigns, as a way to reduce patient-caused delay among those at risk.

\section{References}

1. Farr W. The influence of marriage on the mortality of the French people. Trans Natl Assoc Promot Soc Sci 1858;504:1-24.

2. March L. Some researches concerning the factors of mortality. $J$ $R$ Stat Soc 1912;75:505-38.

3. Ben Shlomo Y, Smith GD, Shipley M, et al. Magnitude and causes of mortality differences between married and unmarried men. J Epidemiol Community Health 1993;47:200-5.

4. US Bureau of the Census. Mortality by marital status, by age race and sex, urban and rural, United States, 1940. Vital Rep $1945 ; 23(2)$.

5. Gove WR. Sex, marital status, and mortality. AJS 1973;79:45-67.

6. Koskenvuo M, Kaprio J, Lonnqvist J, et al. Social factors and the gender difference in mortality. Soc Sci Med 1986;23:605-9.

7. Johnson NJ, Backlund E, Sorlie PD, et al. Marital status and mortality: the national longitudinal mortality study. Ann Epidemiol 2000;10:224-38.

8. De Luca G, Suryapranata H, Ottervanger JP, et al. Time delay to treatment and mortality in primary angioplasty for acute myocardial infarction: every minute of delay counts. Circulation 2004;109:1223-5

9. Fibrinolytic Therapy Trialists' Collaborative Group. Indications for fibrinolytic therapy in suspected acute myocardial infarction: collaborative overview of early mortality and major morbidity results from all randomised trials of more than 1000 patients. Lancet 1994:343:311-22.

10. Eagle KA, Nallamothu BK, Mehta RH, et al. Trends in acute reperfusion therapy for ST-segment elevation myocardial infarction from 1999 to 2006: We are getting better but we have got a long way to go. Eur Heart J 2008;29:609-17.

11. Rogers WJ, Frederick PD, Stoehr E, et al. Trends in presenting characteristics and hospital mortality among patients with ST elevation and non-ST elevation myocardial infarction in the National Registry of Myocardial Infarction from 1990 to 2006. Am Heart J 2008;156:1026-34.

12. Goldberg RJ, Yarzebski J, Lessard D, et al. Decade-long trends and factors associated with time to hospital presentation in patients with acute myocardial infarction: the Worcester Heart Attack Study. Arch Intern Med 2000;160:3217-23.

13. McGinn AP, Rosamond WD, Goff DC Jr, et al. Trends in prehospital delay time and use of emergency medical services for acute myocardial infarction: experience in 4 US communities from 1987-2000. Am Heart J 2005;150:392-400.

14. Dracup K, McKinley S, Riegel B, et al. A randomized clinical trial to reduce patient prehospital delay to treatment in acute coronary syndrome. Circ Cardiovasc Qual Outcomes 2009;2: 524-32.

15. Luepker RV, Raczynski JM, Osganian S, et al. Effect of a community intervention on patient delay and emergency medical service use in acute coronary heart disease: the Rapid Early Action for Coronary Treatment (REACT) trial. JAMA 2000; 284:60-7.

16. Luepker RV. Delay in acute myocardial infarction: Why don't they come to the hospital more quickly and what can we do to reduce delay? Am Heart J 2005;150:368-70.

17. Banks AD, Dracup K. Are there gender differences in the reasons why African Americans delay in seeking medical help for symptoms of an acute myocardial infarction? Ethn Dis 2007; 17:221-7.

18. Moser DK, McKinley S, Dracup K, et al. Gender differences in reasons patients delay in seeking treatment for acute myocardial infarction symptoms. Patient Educ Couns 2005;56:45-54.

19. Tu JV, Donovan LR, Lee DS, et al. Effectiveness of public report cards for improving the quality of cardiac care: the EFFECT study: a randomized trial. JAMA 2009;302:2330-7.

20. Population by sex and age group, by province and territory. Ottawa (ON): Statistics Canada; 2010. Cat. no. 82FOO85-XDB.

21. Lee DS, Austin PC, Rouleau JL, et al. Predicting mortality among patients hospitalized for heart failure: derivation and validation of a clinical model. JAMA 2003;290:2581-7.

22. Ouality of cardiac care in Ontario - report 2. Toronto (ON): Institute for Clinical Evaluative Sciences; 2005. Available: www.ices.on.ca/file/CCORT_EFFECT_Phase1_Report2_final.pdf (accessed 2011 May 17).

23. Alpert JS, Thygesen K, Antman E, et al. Myocardial infarction redefined - a consensus document of the Joint European Society of Cardiology/American College of Cardiology Committee for the redefinition of myocardial infarction. $\mathrm{J} \mathrm{Am} \mathrm{Coll} \mathrm{Cardiol}$ 2000;36:959-69.

24. Gurwitz JH, McLaughlin TJ, Willison DJ, et al. Delayed hospital presentation in patients who have had acute myocardial infarction. Ann Intern Med 1997;126:593-9.

25. Nguyen HL, Saczynski JS, Gore JM, et al. Age and sex differences in duration of prehospital delay in patients with acute myocardial infarction: a systematic review. Circ Cardiovasc Qual Outcomes 2010;3:82-92.

26. Sheifer SE, Rathore SS, Gersh BJ, et al. Time to presentation with acute myocardial infarction in the elderly: associations with race, sex, and socioeconomic characteristics. Circulation 2000; 102:1651-6.

27. Iserson KV, Moskop JC. Triage in medicine, part I: concept, history, and types. Ann Emerg Med 2007;49:275-81.

28. Ikeda A, Iso $\mathrm{H}$, Toyoshima $\mathrm{H}$, et al. Marital status and mortality among Japanese men and women: the Japan Collaborative Cohort Study. BMC Public Health 2007;7:73.

29. Shah BR, Chiu M, Amin S, et al. Surname lists to identify South Asian and Chinese ethnicity from secondary data in Ontario, Canada: a validation study. BMC Med Res Methodol 2010;10:42.

30. Austin PC, Tu JV, Daly PA, et al. The use of quantile regression in health care research: a case study examining gender differences in the timeliness of thrombolytic therapy. Stat Med 2005; 24:791-816.

31. Austin PC, Schull MJ. Quantile regression: a statistical tool for out-of-hospital research. Acad Emerg Med 2003;10:789-97.

32. Steyerberg EW, Eijkemans MJ, Harrell FE Jr, et al. Prognostic modelling with logistic regression analysis: a comparison of selection and estimation methods in small data sets. Stat Med 2000;19:1049-79.

33. Tu JV, Nardi L, Fang J, et al. National trends in rates of death and hospital admissions related to acute myocardial infarction, heart failure and stroke, 1994-2004. CMAJ 2009;180:E118-25.

34. Ingarfield SL, Jacobs IG, Jelinek GA, et al. Patient delay and use of ambulance by patients with chest pain. Emerg Med Australas 2005;17:218-23.

35. Meischke H, Eisenberg MS, Larsen MP. Prehospital delay interval for patients who use emergency medical services: the effect of heart-related medical conditions and demographic variables. Ann Emerg Med 1993;22:1597-601.

36. Canto JG, Shlipak MG, Rogers WJ, et al. Prevalence, clinical characteristics, and mortality among patients with myocardial infarction presenting without chest pain. JAMA 2000;283:3223-9.

37. Brieger D, Eagle KA, Goodman SG, et al. Acute coronary syndromes without chest pain, an underdiagnosed and undertreated high-risk group: insights from the Global Registry of Acute Coronary Events. Chest 2004;126:461-9. 
38. Ting HH, Bradley EH, Wang Y, et al. Factors associated with longer time from symptom onset to hospital presentation for patients with ST-elevation myocardial infarction. Arch Intern Med 2008;168:959-68.

39. Rudisch B, Nemeroff CB. Epidemiology of comorbid coronary artery disease and depression. Biol Psychiatry 2003;54:227-40.

40. Schleifer SJ, Macari-Hinson MM, Coyle DA, et al. The nature and course of depression following myocardial infarction. Arch Intern Med 1989;149:1785-9.

Affiliations: From the Institute for Clinical Evaluative Sciences (Atzema, Austin, Chiu, Wang, Tu), Toronto, Ont.; the Division of Emergency Medicine (Atzema), the Divisions of Cardiology and of General Internal Medicine (Tu) and the McGill University Health Centre (Huynh), Montréal, Que.; and the Department of Cardiac Surgery, New Brunswick Heart Centre (Hassan), Saint John, NB

Contributors: Clare Atzema had full access to all data in the study and takes responsibility for the integrity of the data and the accuracy of the data analysis. Clare Atzema, Peter Austin, Thao Huynh, Ansar Hassan, Maria Chiu, Julie Wang and Jack Tu contributed to study concept and design. Jack Tu acquired the data. Clare Atzema and Peter Austin analyzed and interpreted the data. Clare Atzema drafted the manuscript. Peter Austin, Thao Huynh, Ansar Hassan, Maria Chiu, Julie Wang and Jack Tu critically revised the manuscript for important intellectual content. Clare Atzema and Peter Austin performed the statistical analysis. Jack Tu and Clare Atzema obtained funding.

Funding: This study was supported by the Institute for Clinical Evaluative Sciences (ICES), which is funded by an annual grant from the Ontario Ministry of Health and LongTerm Care (MOHLTC). The project was supported in part by a Canadian Insitutes of Health Research (CIHR) Team Grant in Cardiovascular Outcomes Research and by operating grant NA5703 from the Heart and Stroke Foundation of Ontario (HSFO). Clare Atzema was supported by a Clinician Scientist Award from the HSFO; Peter Austin by a Career Investigator Award from the HSFO; Thao Huynh by CIHR and by the Research Institute and the Department of Medicine of the McGill University Health Centre; Maria Chiu by a CIHR Frederick Banting and Charles Best Canada Graduate Scholarship Doctoral Award, and Jack Tu by a Canada Research Chair in Health Services Research from CIHR and a Career Investigator Award from the HSFO. The opinions, results and conclusions reported in this paper are those of the authors and are independent from the funding sources. No endorsement by ICES or the Ontario MOHLTC is intended or should be inferred. The HSFO had no involvement in the design or conduct of the study, data management or analysis, or manuscript preparation, review, or authorization for submission.

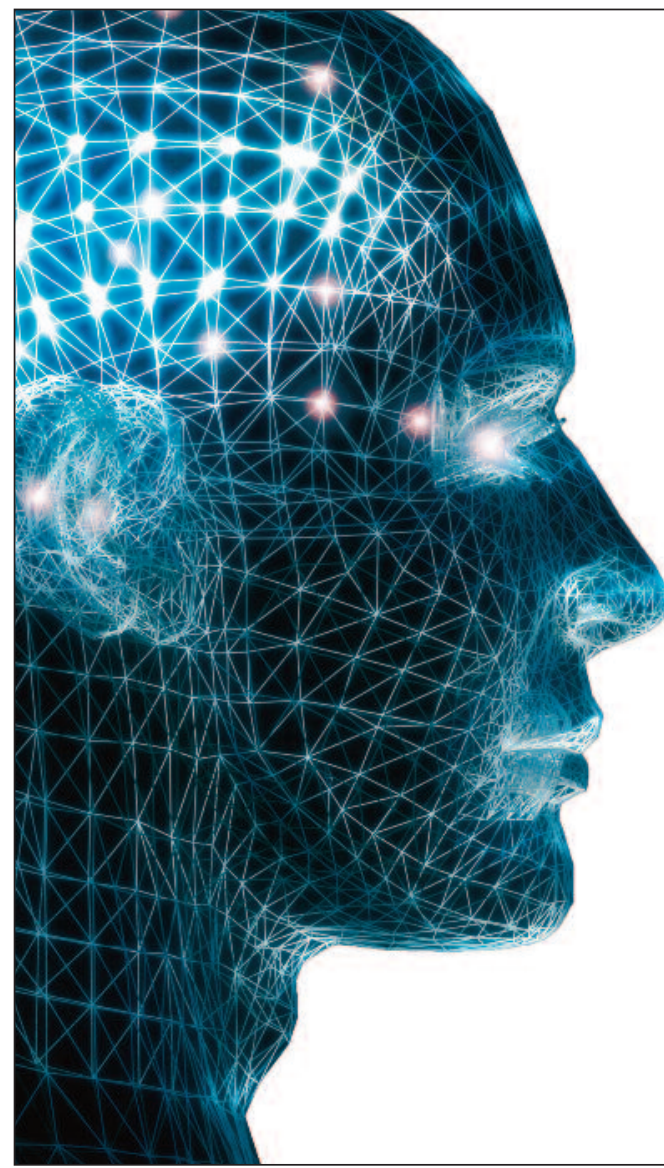

\title{
Be one of the first to know!
}

\author{
And sign up for Weekly Alerts of new content \\ posted on cmaj.ca
}

Don't miss out on online-only news and research articles that you won't see in print.

Go to www.cmaj.ca/cgi/alerts/etoc to sign up!

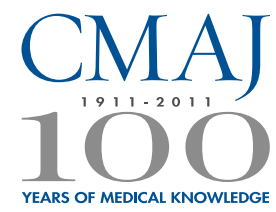

